\title{
Bile duct injury following cholecystectomy
}

\section{Lesão iatrogênica de via biliar pós-colecistectomia}

\author{
Bruno lima linhares'; Aline da Graça Magalhães²; Paula Mariana Soares Cardoso²; Jaime Paula Pessoa Linhares Filho3; \\ José Eudes Bastos Pinho, ACBC-CE'; Marcelo Leite Vieira Costa ${ }^{1}$
}

A $B$ S T R A C T

\begin{abstract}
Objective: To describe the epidemiological, clinical and surgical features of patients with iatrogenic bile duct injury (IBDI) attending the General Hospital of Fortaleza (HGF) during the period from 2005 to 2009. Methods: We conducted a retrospective study of medical records of patients admitted to HGF with the diagnosis of IBDI, evaluating the following variables: gender, age, origin, conditions of cholecystectomy, type of surgery, symptoms, exams performed, surgical findings, classification of injury, treatment, complications, total duration of hospitalization and discharge conditions. Results: There were 27 confirmed cases of IBDI. Two injuries occurred during laparoscopic cholecystectomy cholecystectomy. Only one patient was diagnosed intraoperatively. The most frequent sign was jaundice after cholecystectomy. Hepato-duodenal Y-en-Roux anastomosis was the most often employed surgical technique (85.2\%). Most patients were discharged from hospital in good clinical condition (88.8\%), however, we found high morbidity rates for this disease, exemplified by the multiple hospitalizations and longer hospital stay (mean 31 days). Conclusion: Most injuries occurred during open cholecystectomy, jaundice was the most frequent sign upon admission. There was a high hospitalization length of stay, caused by postoperative complications, which could be explained by delayed diagnosis resulting in a large delay in treatment.
\end{abstract}

Key words: Cholecystectomy. Bile duct injury . Iatrogenic disease.

\section{INTRODUCTION}

B liary calculous disease is one of the most common disorders that occur in humans. The incidence is $10-$ $20 \%$ of the whole adult population on the planet, making laparoscopic cholecystectomy one of the most frequently performed operations in theworld 1 .

The iatrogenic bile duct injury (IBDI) was first described by Sprenge/ in $1891^{2}$ and is one of the most feared complications associated with cholecystectomy. The stenosis of bile duct is a complication that often may cause disastrous consequences, such as biliary cirrhosis, liver failure and, ultimately, death ${ }^{3}$.

During the 1990s, laparoscopic cholecystectomy surpassed the conventional one for the treatment of calculous biliary disease. Unfortunately, despite the numerous advantages of the method, it is estimated that the incidence of IBDI has increased from $0.1-0.2 \%$ to $0.4-0.6 \%{ }^{4}$. Note that IBDI can also occur during other surgical procedures.

The prognosis is directly related to the patient's underlying conditions, as well as the time elapsed between the lesion and its identification and treatment, which is basically the reconstruction of the biliary path, with or without bilio-digestive anastomoses ${ }^{5}$. The Roux-en-Y hepatico- jejunostomy is considered to be the treatment of choice today ${ }^{6}$.

The management of patients with IBDI is quite complex, requiring the skills of experienced hepatobiliary surgeons and specialized tertiary care services in the treatment of this type of injury?

Considering all aspects discussed above and their relevance, we have decided to describe cases of IBDI managed in the General Hospital of Fortaleza (HGF), studying their epidemiological clinical and surgical features.

\section{METHODS}

It is a retrospective cohort study in which we included patients with a diagnosis of post-cholecystectomy bile duct injury assisted and treated at the Fortaleza General Hospital (HGF) during the period from 2005 to 2009.

It was developed in accordance with the regulatory standards and guidelines for research involving humans, being approved by the Ethics and Research Committee of the General Hospital of Fortaleza, obtaining consent to carry out this study, file No. 011010/09.

Work conducted in General Surgery Service of the Fortaleza General Hospital, Ceará - CE, Brazil

1. Surgeon, Fortaleza General Hospital -CE-BR; 2. Medical School Graduate, Ceará State University-CE-BR; 3. Medical School Graduate, Ceará Federal University-CE-BR. 
Data Collection from patient records was made with the aid of a form, which was designed after an extensive literature review, covering the epidemiological and clinical-surgical aspects most relevant to the subject, including: age, gender, origin, patient admission process conditions, type of cholecystectomy (open or laparoscopic). Serum levels of direct and indirect bilirubin, AST, ALT, alkaline phosphatase, gamma-GT and albumin were measured. The presence of complications of the IBDI, type of treatment and patient conditions at discharge were also recorded.

We used, for diagnostic confirmation: Ultrasound (US), Cholangio-MRI (C MRI), Endoscopic Retrograde Cholangiopancreatography (ERCP) and Computerized Tomography (CT) of the abdomen.

For classification of IBDI, we use the one proposed by Bismuth, since most stenoses were late ones ${ }^{8}$.

\section{RESULTS}

Were accompanied and cared for 27 patients with post-cholecystectomy iatrogenic bile duct injuries. We did not considered cases of bile duct stenoses of another etiology. Patients' age ranged between 20 and 73 years (mean 43.4 years). On the distribution by gender, three were male $(11.1 \%)$ and $24(88.9 \%)$ female.

Two patients $(7.4 \%)$ were submitted to laparoscopic cholecystectomy on the HGF, while 25 (92.6\%) came from secondary hospitals in Fortaleza or other municipalities. Amongst the patients from other hospitals, 15 were referred by hospitals in the interior of the State of Ceará, three came from secondary hospitals of the capital (Fortaleza), one was from another State and six of them had no origin reported on their charts.

In two patients the injury occurred during laparoscopy, and in 23 (92.0\%), during the laparotomy. In two patient records there was not enough information to assert the access applied for cholecystectomy. With respect to whether intraoperative cholangiography was performed or not, all patients from other hospitals did not have these data in their records. This exam was carried out in only one of our patients.

Only one case (3.7\%) of IBDI was diagnosed and treated intraoperatively. The remaining cases were diagnosed postoperatively (96.3\%). The time elapsed between the laparoscopic cholecystectomy and the diagnosis of IBDI varied greatly, from four days until more than three years.

Considering the cases diagnosed postoperatively (26 patients), all patients were symptomatic at admission. The time elapsed between the laparoscopic cholecystectomy and the onset of symptoms varied widely, from one day up to three years. Disregarding the intraoperatively diagnosed case and another without a properly filled record, 18 patients (72.0\%) had early symptoms (<3 months) and $28.0 \%$ displayed later symptoms (> 3 months).

The most frequent symptoms were, in descending order of frequency: jaundice, choluria, fecal acholia, pruritus, abdominal pain, fever, nausea and vomiting, weight loss and abdominal distension (Figure 1). By the time of admission to our service, three patients had cholangitis, seven choleperitoneum, four biloma, five had a diagnosis of biliary fistula and three abdominal sepsis. We did not identify cases of death resulting from the bile duct injury.

The time elapsed between the laparoscopic cholecystectomy and the admission to the HGF varied from four days to four years. Disregarding the case intraoperatively diagnosed in HGF, only $30.7 \%$ patients were referenced within a month from the time of the injury. The rest $(69.3 \%)$ were referenced after a month, showing symptoms of cicatricial stenosis.

Variations and averages of the results of laboratory tests performed at the time of admission are shown in table 1.

Ultrasound was performed in 19 patients, C-MRI in 14, ERCP in 13 and abdominal CT in six.

All patients in our study were treated surgically. The Roux-en-Y hepatico-jejunostomy was the most employed technique, being held in 23 patients (85.2\%). In one patient an anastomosis between the hepatic duct and the duodenum was performed. In three patients we conducted a choledochoplasty over a T-tube drain.

We found, through surgical description data, that ten patients had Bismuth type II injury and another ten had type III. In the other patients it was not possible to classify the injury.

After correction of IBDI 37\% of patients developed postoperative complications. There were four cases of wound infection; two cases of biliary fistula treated conservatively and one case of incisional hernia, corrected with hernioplasty. Three cases evolved with stenosis of the hepatico-jejunostomy.

The time of hospital stay varied considerably, from seven up to 87 days, with an average of 31 days.

At the time of discharge from the last admission to our service, 24 patients were cured, without sequelae

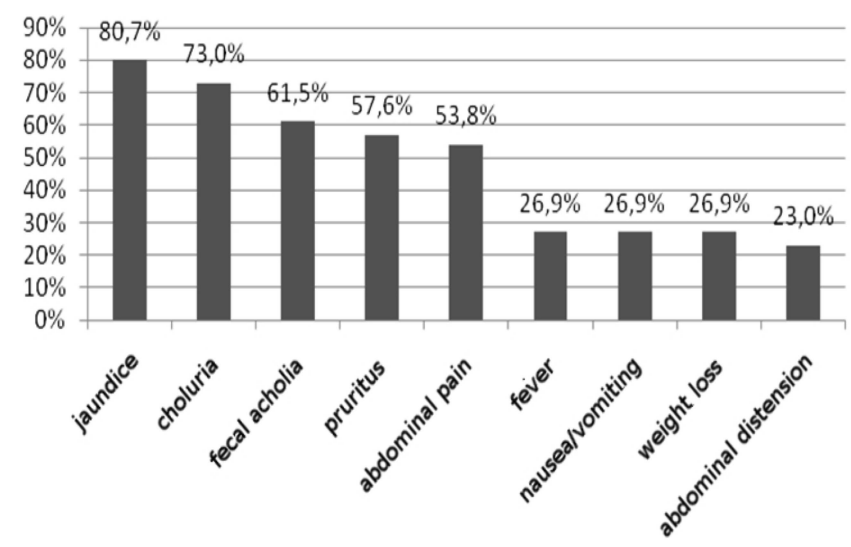

Figure 1 - Relative frequency of symptoms reported by patients. 
and with good conditions. One patient still awaits liver transplant. Two patients were discharged with the biliary drain, to be subsequently readmitted to definitive surgical treatment, but lost follow-up.

\section{DISCUSSION}

The benign stenosis of bile ducts, according to Marson et $a^{\beta}$, include all congenital or acquired stenoses, the latter being secondary to inflammatory or cicatricial processes of various etiologies (chronic pancreatitis, choledocholithiasis, hepatic abscess, pyogenic cholangitis, recurrent sclerosing cholangitis, post-radiation and iatrogenic injury during surgical act). Most often, the injury is iatrogenic (71 to 95\%), the cholecystectomy, either by laparotomy or by laparoscopy, being the procedure most commonly associated with these lesions. They are followed by abdominal trauma and gastroduodenal operations.

For Aguiar et $a^{\beta}$, iatrogenic bile duct injuries are a priority public health problem, given their high morbidity, which was confirmed in our study, affecting a substantial number of patients and reaching predominantly an economically active age group.

Although there is no consensus, most studies show an increase in the incidence of these injuries. With the advent of laparoscopy, the rate of serious bile duct injuries after cholecystectomy had a discreet increase of up to $0.8 \%$, whilst the one related to the open route remained between 0.2 to $0.3^{3} \%$.

Our results showed that the majority of injuries (92.0\%) occurred after laparotomy, which does not agree with the largest study ever published on the subject ${ }^{10}$, which assessed 156 patients with iatrogenic bile duct injury, with an average follow-up of 57.5 months and found that in 118 patients $(75.6 \%)$ the injury happened during laparoscopic cholecystectomy.

Despite the large number of cholecystectomies held in the Fortaleza General Hospital (average 140 per year) and the fact that it is a training hospital for surgery residents, only two cases of bile duct injury were observed in a period of five years, one during laparotomy and another during laparoscopy.
Although prompt recognition of bile duct injuries is of fundamental importance to the better recovery of the patient, it is immediately recognized only in less than half of cases. The late identification of such injury may lead to serious complications, such as biliary cirrhosis, liver failure and death ${ }^{6}$. Only $15-30 \%$ of injuries of the biliary tract are diagnosed during the initial procedure ${ }^{11}$. In our study, only one case (3.7\%) was intraoperatively diagnosed, enabling immediate correction. Most lesions were lately diagnosed, a few months to years after cholecystectomy.

Patients with bile duct injuries not diagnosed during the initial operation may present in different ways. One must always suspect IBDI when the following events occur after cholecystectomy: postoperative jaundice, peritonitis, bloating, imaging exams revealing intrahepatic biliary dilation. Late presentations can include recurrent cholangitis and secondary biliary cirrhosis ${ }^{11}$. In our series, the main form of presentation was post-cholecystectomy early jaundice. However, some patients were admitted to our service in serious conditions, requiring urgent surgical treatment. A high pecentage of patients (26.9\%) presented with choleperitoneum at admission, and three had abdominal sepsis.

Early transfer to specialized centers with experienced surgeons in surgery of bile ducts can reduce the number of reoperations, the time for definitive repair, complications and mortality 4 . Most patients were referred to our service belatedly, showing symptoms of cicatricial biliary stenoses.

Imaging exams are of great importance in the diagnosis and surgical programming of IBDI cases. In our study, we used the same resources described in similar series $^{12}$. The ultrasound showed sub-hepatic liquid collection, proximal bile duct dilatation and bile duct discontinuity. Abdominal CT and C-MRI showed, besides the dilatation of bile ducts, the level and extent of the injury. ERCP evidenced the thin distal biliary tree and the absence of visible proximal bile duct. Other tests that can be performed are percutaneous, trans-hepatic cholangiography and cholangiography by the T-tube drain.

Among the various existing classifications for IBDI, we call attention to the Bismuth classification $(1982)^{8}$, more used for late stenoses resulting, in most cases, from thermal

Table 1 - Results of laboratory tests at admission.

\begin{tabular}{lrr}
\hline Exam & Variation & Average \\
\hline Total bilirubin (mg/dl) & $0.5-38.3$ & 9.3 \\
Direct bilirubin (mg/dl) & $0.1-26.5$ & 6.9 \\
Indirect bilirubin (mg/dl) & $0.1-11.7$ & 2.4 \\
AST (IU/dl) & $12-388$ & 101.5 \\
ALT (IU/dl) & $7-469$ & 135.7 \\
Alkaline phosphatase (IU/L) & $438-13983$ & 2147 \\
Gamma-GT (lu/L) & $76-1722$ & 436 \\
Albumin (g/dl) & $2.6-4.2$ & 3.5 \\
\hline
\end{tabular}


injury or ligatures too close to bile duct, with inflammatory reaction and subsequent stenosis, not encompassing the acute injuries. Although older, it displays a good correlation with the final result after surgical repair, being quite helpful in the decision of the surgeon as to the best technique to be employed ${ }^{13}$

The scarcity of data from patient records and late IBDI presentation hampered the classification. It was noted that 20 patients had serious injury, in the hilar plate or next to it, needing, to their correction, very high, difficult to achieve anastomoses. In other patients, it was not possible to classify the injury given the lack of information on the records.

The first goal in the treatment of IBDI should be the control of sepsis and bile leaks. Surgical reconstruction after resolution of the initial septic state is not urgent and could be held 5-6 weeks later ${ }^{4}$. In our series, four patients were initially operated by choleperitoneum, only having their biliary trees drained, and weeks after, readmitted for final surgery.

With respect to the type of therapy being used for these patients, there are still some controversial aspects, being preferentially held initial via endoscopic approach and, when this is not effective, choosing the surgical reconstructions for therapeutic approach. The goal of surgery in these cases is the reconstitution of the biliary path to the food tract $^{6}$. In relation to the surgical procedure, the Rouxen- $Y$ hepatico-jejunostomy is the best therapeutic option and the most frequently employed ${ }^{9,10}$, which was also recorded in our study, where $85.2 \%$ of patients have undergone this type of treatment.
Despite the mortality observed in our study, $37.0 \%$ of cases showed some postoperative complication rate similar to that described by Sicklick in his series $(42.9 \%)^{4}$. Most of these complications were handled clinically; however, three patients needed to be reoperated for stenosis of the hepatico-jejunostomy, two had cholangitis and were treated with new hepatico-jejunostomy; the third patient evolved with repetition cholangitis, secondary biliary cirrhosis, portal hypertension, intrahepatic calculi and is currently queued for liver transplantation. In this case, after attempting to correct stenosis of hepatico-jejunostomy, access to the hilar plate was not possible, given the difficulty due to adhesions and fibrosis. The patient remained, therefore, without bile continuity, being handled with external percutaneous drainage of the biliary tree while awaiting transplantation. This case exemplifies the morbidity that IBDI may cause.

In a report of three cases, Fernández et a/14 describe that, in addition to the bile duct injury associated with chronic cholestasis and episodes of cholangitis, another indication for transplantation is the injury to liver vessels, mainly the hepatic artery, resulting in fulminant liver failure.

Most of the injuries occurred during cholecystectomy by laparotomy and jaundice is the most frequent sign at admission. While $88 \%$ of patients have been discharged in good clinic condition, we observed a lengthy hospital stay, consequence of the postoperative complications, which could be explained by the late diagnosis and delayed treatment.

\title{
R E S U M O
}

\begin{abstract}
Objetivo: Descrever os aspectos epidemiológicos, clínicos e cirúrgicos dos pacientes com lesão iatrogênica das vias biliares (LIVB) atendidos no Hospital Geral de Fortaleza (HGF) durante o período de 2005 a 2009. Métodos: Realizou-se estudo retrospectivo dos prontuários dos pacientes internados no HGF diagnóstico de LIVB, obtendo-se as seguintes variáveis: sexo, idade, procedência, condições da colecistectomia, tipo de operação, sintomatologia, exames realizados, achados cirúrgicos, classificação da lesão, tratamento, complicações, tempo total de internamento e condições de alta. Resultados: Foram confirmados 27 casos de LIVB. Duas lesões ocorreram durante a colecistectomia videolaparoscópica. Apenas um paciente foi diagnosticado no intra-operatório.. O sinal mais freqüente foi a icterícia pós-colecistectomia. A hepático-jejunostomia em "Y" de Roux foi a técnica cirúrgica mais empregada (85,2\%). A maioria dos pacientes recebeu alta hospitalar em boas condições clínicas (88,8\%); no entanto, constatou-se, a elevada morbidade desta patologia, exemplificada pelos múltiplos internamentos e longa permanência hospitalar (média de 31 dias). Conclusão: A maioria das lesões ocorreu durante a colecistectomia por laparotomia, a icterícia foi o sinal mais freqüente quando da internação Verificou-se uma elevada permanência hospitalar causada pelas complicações pós-operatórias o que poderia ser explicado pelo diagnóstico tardio ocasionando um grande retardo no tratamento neste pacientes.
\end{abstract}

Descritores: Colecistectomia. Lesão de via biliar. Doença iatrogênica.

\section{REFERENCES}

1. Townsend CM Jr., Beauchamp RD, Evers M, et al, editores. Sabiston, Tratado de Cirurgia. A base biológica da prática cirúrgica moderna. $18^{\mathrm{a}}$ ed. Philadelphia: Elsevier Saunders. 2010; p. 1460
2. Sprengel $\mathrm{O}$. Uber einen fall von extirpation der gallenblase mit anlegung einer kommunikation zwischen ductus choledochus und duodenum. Arch Klin Chir 1891; 156:470.

3. Marson AC, Mali Júnior J, Oliveira RG, Valezi AC, Brito EM, Libos Júnior F. Tratamento cirúrgico das estenoses da via biliar. Rev Col Bras Cir 2004; 31(4):224-7. 
4. Sicklick JK, Camp MS, Lillemoe KD, Melton GB, Yeo CJ, Campbell $K A$, et al. Surgical management of bile duct injuries sustained during laparoscopic cholecystectomy: perioperative results in 200 patients. Ann Surg 2005; 241 (5):786-792; discussion 793-5.

5. Abdel Wahab M, el-Ebiedy G, Sultan A, el-Ghawalby N, Fathy O, Gad el-Hak, et al. Postcholecystectomy bile duct injuries: experience with 49 cases managed by different therapeutic modalities. Hepatogastroenterology 1996; 43(11):1141-7.

6. Jablonska B, Lampe P. latrogenic bile duct injuries: etiology, diagnosis and management. World J Gastroenterol 2009; 15(33):4097-104.

7. Melton GB, Lillemoe KD, Cameron JL, Sauter PA, Coleman J, Yeo CJ. Major bile duct injuries associated with laparoscopic cholecystectomy: effect of surgical repair on quality of life. Ann Surg 2002; 235(6):888-95.

8. Bismuth H. Postoperative strictures of the bile ducts. In: Blumgart LH, editor. The biliary tract. New York: Churchill-Livingstone;1982. p.209-18.

9. Aguiar GB, Oliveira CIB, Silva Júnior JBS, Santos LS, Vieira SC. Lesão iatrogênica de vias biliares. Rev Col Bras Cir 2005; 32(2) :6973.

10. Lillemoe KD, Melton GB, Cameron JL, Pitt HA, Campbell KA, Talamin $M A$, el al. Postoperative bile duct strictures: management and outcome in the 1990s. Ann Surg 2000; 232(3):430-41.

11. de Santibáñes $E$, Ardiles $V$, Pekolj J. Complex bile duct injuries: management. HPB 2008; 10(1):4-12.
12. Wu JS, Peng C, Mao XH, Lv P. Bile duct injuries associated with laparoscopic and open cholecystectomy: sixteen-year experience. World J Gastroenterol 2007; 13(16):2374-8.

13. Milcent M, Santos EG, Bravo Neto GP. Lesão iatrogênica da via biliar principal em colecistectomia videolaparoscópica. Rev Col Bras Cir 2005; 32(6):332-6.

14. Fernández JA, Robles R, Marín C, Sánchez-Bueno F, Ramirez P, Parrilla P. Laparoscopic iatrogeny of the hepatic hilum as an indication for liver transplantation. Liver Transpl 2004; 10(1):14752

Received on: 16/02/2010

Accepted for publication: 19/04/2010

Conflict of interest: none

Funding source: none

\section{How to cite this article:}

Linhares BL, Magalhães AG, Cardoso PMS, Linhares Filho JPP, Pinho JEB.Post-cholecystectomy iatrogenic bile duct injury. Rev Col Bras Cir. [periódico na Internet] 2011; 38(2). Disponível em URL: http:// www.scielo.br/rcbc

\section{Mailing address:}

Bruno Lima Linhares

E-mail: blima_linhares@hotmail.com 